\title{
Article
}

\section{Alleles of the GRF3-2A Gene in Wheat and Their Agronomic Value}

\author{
Mikhail S. Bazhenov ${ }^{1, * \mathbb{D}}$, Anastasiya G. Chernook ${ }^{1,2}{ }^{\mathbb{D}}$, Ludmila A. Bespalova ${ }^{3}$, Tatiana I. Gritsay ${ }^{3}$, \\ Nadezhda A. Polevikova ${ }^{3}$, Gennady I. Karlov ${ }^{1}{ }^{\mathbb{D}}$, Lubov A. Nazarova ${ }^{1}$ and Mikhail G. Divashuk ${ }^{1,2} \mathbb{B}$ \\ 1 Laboratory of Applied Genomics and Crop Breeding, All-Russia Research Institute of Agricultural \\ Biotechnology, 127550 Moscow, Russia; irbis-sibri@yandex.ru (A.G.C.); karlovg@gmail.com (G.I.K.); \\ lpukhova@yandex.ru (L.A.N.); divashuk@gmail.com (M.G.D.) \\ 2 Kurchatov Genomics Center-ARRIAB, All-Russia Research Institute of Agricultural Biotechnology, \\ 127550 Moscow, Russia \\ 3 National Center of Grain Named after P.P. Lukyanenko, Department of Breeding and Seed Production of \\ Wheat and Triticale, Central Estate of KNIISH, 350012 Krasnodar, Russia; bespalova_1_a@rambler.ru (L.A.B.); \\ t_i_gritsay@mail.ru (T.I.G.); nadyapolevikova@gmail.com (N.A.P.) \\ * Correspondence: mikhabazhenov@gmail.com
}

check for updates

Citation: Bazhenov, M.S.; Chernook, A.G.; Bespalova, L.A.; Gritsay, T.I.; Polevikova, N.A.; Karlov, G.I.; Nazarova, L.A.; Divashuk, M.G. Alleles of the GRF3-2A Gene in Wheat and Their Agronomic Value. Int. J. Mol. Sci. 2021, 22, 12376. https://doi.org/10.3390/ijms222212376

Academic Editors: Isabel Marques, Ana I. Ribeiro-Barros and José C. Ramalho

Received: 27 September 2021 Accepted: 15 November 2021 Published: 16 November 2021

Publisher's Note: MDPI stays neutral with regard to jurisdictional claims in published maps and institutional affiliations.

Copyright: (c) 2021 by the authors. Licensee MDPI, Basel, Switzerland. This article is an open access article distributed under the terms and conditions of the Creative Commons Attribution (CC BY) license (https:// creativecommons.org/licenses/by/ $4.0 /)$.

\begin{abstract}
The Growth-regulating factors (GRF) are a family of plant-specific transcription factors that have roles in plant growth, development and stress response. In this study the diversity of the TaGRF3-2A (TraesCS2A02G435100) gene was investigated in Russian bread wheat germplasm by means of next generation sequencing and molecular markers, and the results compared with those from multiple wheat genome and exome sequencing projects. The results showed that an allele possessing c.495G > T polymorphism found in Bezostaya 1 and designated as TaGRF3-2Ab, is connected with earlier heading and better grain filling under conditions of the Krasnodar Krai. TaGRF3-2Ab is more frequent among Russian winter wheat cultivars than in other germplasms found in the world, implying that it is adaptive for the Chernozem region. A new rare mutation of the TaGRF3-2A was found in the spring wheat cultivar Novosibirskaya 67. The molecular markers developed will facilitate utilization of TaGRF3-2A mutations in future agronomic studies and wheat improvement. Albeit GRF3-2Ab may be good at maintaining high milling quality of the grain, it should be used with caution in breeding of winter wheat cultivars in the perspective of climate change.
\end{abstract}

Keywords: GRF; transcription factor; diversity; NGS; earliness; kernel weight; test weight

\section{Introduction}

Growth-Regulating Factors (GRF) are a family of plant-specific transcription factors (TF) that have roles in plant growth, development and stress response [1]. The first GRF gene was characterized in rice as a factor involved in stem elongation under flooding or in response to gibberellic acid [2]. Later the GRF TF genes were identified in the model plant species Arabidopsis thaliana, as well as a number of agricultural crops $[1,3,4]$. These genes are mainly expressed in young growing tissues and organs $[1,3,5]$.

The protein sequence of the GRF TF contains two conserved domains, QLQ (Gln, Leu, Gln) and WRC (Trp, Arg, Cys) in the N-terminus. The C-terminal region of GRF proteins is variable and may have transcriptional activation activity. The WRC domain consists of a nuclear localization signal and a DNA-binding motif and is involved in binding to cis-acting regions of gene promoters [2,3]. The QLQ domain is involved in interaction with GRF-interacting factor proteins (GIF) [6]. GIF proteins through their SNH (SYT Nterminal homology) domains interact with GRF proteins to form functional complexes that participate in regulation of expression of downstream genes [5]. DELLA proteins, accumulation of which is characteristic of green revolution varieties, can interfere with OsGRF4-GIF1 interaction [7]. 
The level of GRF gene expression is in part regulated by miRNA396 in the posttranscriptional stage. Thus, GRF genes participate in regulation of the same growth, development and stress-response processes as miRNA396 [8].

GRF TFs are involved not only in gibberellin, but also in other plant hormone signaling pathways. Auxin-response factors regulates expression of some GRF genes, like AtGRF5 and AtGRF6 in Arabidopsis, that lack miRNA396 regulation [9]. On the other hand, upregulation of OsGRF6 in rice plants, having the miRNA396 blocked by target mimicry, activates auxin biosynthesis and signaling, stimulating development of auxiliary branches and spikelets in panicle [10]. Enhanced expression of OsGRF4 in rice activates brassinosteroidresponsive genes that enhances the growth of seedlings and source leaves, and promotes grain development. Enhanced brassinosteroid responsiveness may in turn change the level of gibberellins in plants [11].

In Arabidopsis, GRF genes positively regulate leaf growth and are involved in regulation of the stress response to heat, drought, salinity and diseases [3,12]. In rice higher expression of OsGRF4 was shown to be connected to higher 1000 kernel weight and grain yield [11,13], higher nitrogen uptake and assimilation in plants carrying the Slr1 gibberellin-insensitive reduced height gene [7]. In rapeseed GRF2 was found to enhance seed oil production by increasing leaf area and photosynthetic efficiency [4]. Some rare alleles of TtGRF4- $A$ (a homolog of TaGRF9-6A) associated with increased grain weight were found in wild emmer wheat [14]. Thus, gain-of-function mutations of the GRF genes have great potential for increasing yields of agricultural crops through increasing the leaf area, the size of fruit organs and nutrient use efficiency [15].

In bread wheat (Triticum aestivum L.) $30 \mathrm{TaGRF}$ genes were phylogenetically divided into four groups. They were designated using numbers from 1 to 12 , each number being unique for a group of homeologs, and a chromosome name [1]. These genes are highly expressed in growing tissues including stem meristem and reproductive organs [1]. The level of expression of the TaGRF genes changes significantly under osmotic, drought or salt stress $[1,5]$.

In this study we investigated the TraesCS2A02G435100 gene of bread wheat, which is TaGRF3-2A according to the nomenclature of Huang et al. (2021), and is known as TaGRF3 according to Zan et al. (2020) [1,5]. This gene was chosen as one of the most similar to the rice OsGRF4 gene with the highest percentage of query cover in BLAST output (however the most similar to OsGRF4 are TaGRF9-6A, $-6 B$ and $-6 D$ ). The TaGRF3-2A gene is primarily expressed in shoot apical meristem, stigma and ovary, seeds and young leaves. Also, it seems to be responsive to phosphorous starvation and drought stress [1].

\section{Results}

\subsection{TaGRF3-2A Alleles}

As a result of the next-generation sequencing of the polymerase-chain-rection-amplicons of the TaGRF3-2A gene (TraesCS2A01G435100) and its flanking regions in 19 winter bread wheat cultivars (Table S1), and comparing them with the genome sequences of 13 more varieties that were included in the Wheat 10+ Genomes Project [16] and the genome of the Chinese Spring bread wheat [17] (a total of 33 varieties of bread wheat), we found a total of 21 haplotypes. The considered region on wheat chromosome 2A covered 1,075 nucleotides before the start codon, and 1,389 nucleotides after the stop codon of the TaGRF3-2A gene, completely capturing the $5^{\prime}$ and $3^{\prime}$ untranslated regions (UTR) and part of the promoter. Also, in spelt wheat PI428198 (Triticum spelta L.), wild emmer wheat Zavitan (Triticum dicoccoides (Koern. ex Aschers. Et Graebn.) Schweinf.) and diploid wheat (Triticum urartu Thum. ex Gandil.), that were included in the comparison, three more haplotypes were found $[16,18,19]$. The T. urartu haplotype differed from the bread wheat haplotypes in multiple unique single-nucleotide variants, the haplotype of wild emmer had fewer differences, and the spelt haplotype did not have unique point mutations and differed only by a combination of the highly variable single nucleotide polymorphism (SNP) and the length of a microsatellite in the $5^{\prime} \mathrm{UTR}$. 
In the promoter of the gene, we found a frequently occurring polymorphism chr2A:g.687048627G>C (sequence variations are described according to HGVS recommendations, IWGSC RefSeq v1.0 wheat genome is used as reference) [20]. At this position, most varieties of bread wheat, as well as its wild relatives included in our study, have nucleotide variant ' $C$ ', whereas wheat accessions Chinese Spring, Jagger, Lancer, CDC Stanley, Norin 61 and Novosibirskaya 67 have variant ' $G$ '. Analysis of the promotor sequence using the PlantPAN 3.0 database showed that variant ' $G$ ' gives an additional basic helix-loop-helix transcription factor binding site to the promoter. Several minor frequency SNPs were found in the promoter: an alternative variant of the polymorphism chr2A:g.687048382C $>\mathrm{T}$ is present in cultivars Grom and Altigo, variant ' $\mathrm{T}$ ' of the polymorphism chr2A:g.687048137G $>$ T is present in varieties Velena and Paragon. Variant ' $G$ ' of the polymorphism chr2A:g.687048328A $>\mathrm{G}$ is present only in T. urartu (PI428198) and T. dicoccoides (Zavitan). In the considered region of the promoter (chr2A:g.687047878_687048697) we found 15 unique single-nucleotide variants in the T. urartu haplotype.

In the $5^{\prime} \mathrm{UTR}$ of the Grf3-2A gene, there is a microsatellite repeat $(\mathrm{AG})_{\mathrm{n}}$, where the number of repeats $n$ varies from 11 to 37 . Some variants of the microsatellite differ in loss of a single nucleotide A, resulting in a repeat length of 55 and 61 nucleotides (Figure 1). The wild emmer wheat Zavitan has a deletion of 12 nucleotides c.-102_-91del at a short distance before the microsatellite, and also a single nucleotide substitution c.-140A $>\mathrm{G}$ in the $5^{\prime}$ UTR.

a. $14 ; c .1$
a. $15 ; a .17$
a. 16
a. 7
a. 2
a. $12 ; b .1$
a. $3 ; b .2$
a. 8
a. 13
b. 4
a. $4 ;$ a. 6
d. 1
b. 5
a. $1 ; b .3$
a. 5
a. 9
a. 10
a. 11

\begin{tabular}{|c|c|c|c|c|c|}
\hline & & 20 & 40 & 60 & \\
\hline & & AAC & & $=--$ & 22 \\
\hline & & $\mathrm{AAAG}$ & ACAC------ & & 28 \\
\hline AGAC & & GAGAGZ & ACA EACACACACACAC--- - & --- & 40 \\
\hline$A G$ & GAC & GAGAGA & $A C A C A C A C A C A G A G A C A$ & ----------- & 42 \\
\hline GAE & & GAGAGE & ACAGACACACACACACACAC & 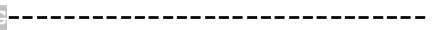 & 4 \\
\hline AAA: & GAG & GAGAGR & CAACACACACACACAGACAC & ------------- & 46 \\
\hline AGAG & GAC & GAGAC & CACACACACACACACACAE & 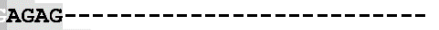 & 18 \\
\hline AGAG & GAG & GAGAG & 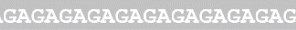 & 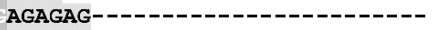 & 50 \\
\hline$A G E$ & BA & GAGAC & CAEACACACACACAEACAC & AGAGAGAGAG--- - - - - & 4 \\
\hline AGAGAG & GAA & GAGAG & CAACACACACACA CAACACAE & 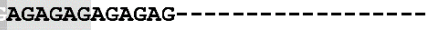 & 5 \\
\hline AGAGAG & GAGA & GAGAG: & ACACACACACA CA CAAEACAC & AGAGAGAGAGAG- - & 56 \\
\hline AGAGAG & GAGA & GAGAGZ & 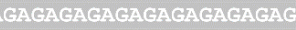 & AGAGAGAGAGAGAG-- - - & 58 \\
\hline AGAG & GAC & GAGAG & 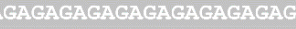 & AGAGAGAGAGAGAGAGAG- & 61 \\
\hline AGAC & GAG & GAGAG & CAACACACACACA CHAACAE & AGAGAGAGAGAGAGAGAG- $-1--1---$ & 52 \\
\hline$A G Z$ & & GAGAC & CAACACACACACACACACAC. & AGAGAGAGAGAGAGAGAGAG --------- & 4 \\
\hline & & & CAGACACAGACACACACAC & AGAGAGAGAGAGAGAGAGAGAG $-\cdots$ & 6 \\
\hline AGAC & $A G$ & GAGAGZ & 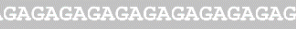 & AGAGAGAGAGAGAGAGAGAGAGAG- & 58 \\
\hline AGAGA & & AGAC & AACACACACACACACAGACAC & AGAGAGAGAGAGAGAGAGAGAGAGAGA & 4 \\
\hline
\end{tabular}

Figure 1. Microsatellite length variation in the $5^{\prime} U T R$ of the GRF3- $2 A$ gene detected by sequencing. The GRF3-2A haplotypes are indicated in the left. An asterisk (*) in the upper line marks each 10-th nucleotide in the alignment between the numbers.

T. urartu PI428198 has two single-nucleotide substitutions c. ${ }^{* 285 A}>\mathrm{G}$ and c. ${ }^{* 312 \mathrm{~A}>\mathrm{T}}$ in the $3^{\prime} \mathrm{UTR}$, and the bread wheat CDC Landmark has a substitution c. ${ }^{* 8 C}>\mathrm{T}$.

In the $3^{\prime}$-end flanking region immediately after the transcription stop site, T. urartu PI428198 has a single nucleotide substitution chr2:g.687052487C $>$ T, and the wild emmer Zavitan has a deletion of two nucleotides at the same point—chr2:g.687052487_687052488del.

Within the introns of the gene, differences from the reference Chinese Spring genome (IWGSC RefSeq v1.0) were found only in T. urartu. T. urartu accession PI428198 has an insertion of three nucleotides c.325+32_+33insTCC, as well as three single-nucleotide substitutions, c. $325+169 \mathrm{G}>\mathrm{C}$, c.326-39A $>\mathrm{G}$, and c.326-174A $>\mathrm{G}$, in the second intron. Singlenucleotide substitutions c. $689+136 \mathrm{~A}>\mathrm{G}$ and c. $689+241 \mathrm{~T}>\mathrm{C}$ were found in the third intron.

In the protein-coding sequence of the GRF3-2A gene, a deletion of nine nucleotides c.126_134del was detected in the second exon in Novosibirskaya 67. This mutation led to the loss of three glutamine residues in the protein molecule in the polyglutamine region p.(Gln42_Gln44del). In the third exon, we found a c.495G > T polymorphism that is frequent among Russian winter wheat cultivars, leading to the replacement of amino acid residue glutamine with histidine p.(Gln165His). In the third exon of the T. urartu gene there are two adjacent single-nucleotide substitutions relative to the reference genome-c.528G $>C$ and c.530C $>\mathrm{G}$, which should result in the replacement of two consecutive amino acids in 
the protein p.(Gln176_Ala177delinsHisGly). In the 4th exon, T. urartu also has a c.729C>G missense variant, which results in a p.(Asp243Glu) amino-acid substitution.

\subsection{Protein Isoforms}

Following the above-described amino acid substitutions, 4 isoforms of the GRF3-2A protein were found among the examined wheat accessions. According to the frequencies of occurrence, we designated them as follows: A-the most frequent isoform, presents in Chinese Spring and most other cultivars, B-frequently found among Russian winter cultivars, C-the isoform characteristic of T. urartu, and D-a mutant form found only in Novosibirskaya 67 (Figure S1). Among accessions in which the TaGRF3-2A was completely sequenced, isoform $B$ was present mainly among cultivars developed at Krasnodar. The correspondence of isoforms to amino acid substitutions, as well as the estimated significance of the amino acid changes for biological function of the protein, predicted by PROVEAN, are shown in Table 1. Isoform B, according to PROVEAN, has a functionally significant amino acid substitution. However, no mutation found in this study disturbed the WRC or QLQ conserved domains of the protein (Figure S1).

Table 1. GRF3-2A protein isoforms and functional significance of amino acid differences.

\begin{tabular}{cccc}
\hline Isoform. & Differences in Protein Sequence & PROVEAN Score & Representative Accessions * \\
\hline A & - & - & Chinese Spring \\
\hline B & Gln165His & $-2.601 * *$ & Stan, Vassa, Vid \\
\hline \multirow{2}{*}{ C } & Gln176_Ala177delinsHisGly & -1.224 & \multirow{2}{*}{ PI428198 (T. urartu) } \\
\cline { 2 - 3 } & Asp243Glu & 0.524 & \\
\hline D & Gln42_Gln44del & 0.821 & Novosibirskaya 67 \\
\hline
\end{tabular}

* If not specified, the species is Triticum aestivum L. ${ }^{* *}$ Variants that have a score lower than -2.5 are assumed to be deleterious in protein biological function.

\subsection{Phylogenetics of Protein Sequences}

Phylogenetic analysis of the predicted amino-acid sequences of the GRF3-2A protein showed that isoform C characteristic of T. urartu is the most ancient, whereas isoform B is the newest (Figure 2). Isoform D, unique for Novosibirskaya 67, is a bit closer to the root of the tree than isoform A, apparently due to the proteins GRF3-2B and GRF3-2D, used as outgroup, having a smaller number of consecutive glutamine residues than GRF3-2A ( 5 vs. 7 , beginning from 38 or 39 residue). Isoform $\mathrm{D}$ has 4 glutamine residues in that part of the molecule (Figure S1).

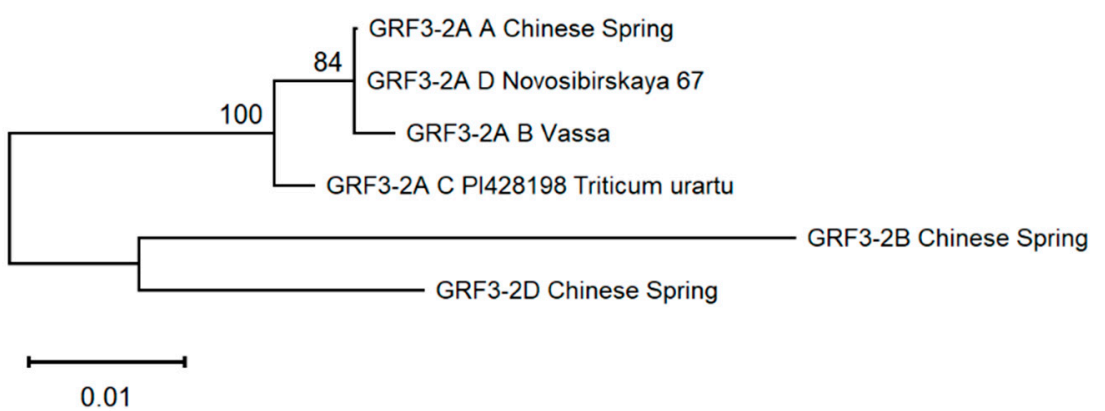

Figure 2. Molecular phylogenetic tree of GRF3-2A protein isoforms. GRF3-2B and GRF3-2D proteins of Chinese Spring were taken as outgroups.

\subsection{Allele Designation}

For further discussion, we designated the various haplotypes (alleles) of the GRF3-2A gene together with its flanking regions with small letters in accordance with the encoded protein isoforms $(a, b, c, d)$ and the number after a dot assigned in accordance with the frequency of occurrence (1-for the most frequent, 2, 3, etc.-for rarer haplotypes) within each group of haplotypes encoding the same protein. The sequences of all haplotypes are 
represented in Supplementary Materials in FASTA format, the wheat accessions in which they were found are listed in Table S2, the frequency of occurrence among the sequenced accessions is listed in Table S3.

\subsection{Allele Phylogenetic Analysis}

The phylogenetic analysis of the Grf3-2A and flanking region haplotypes was carried out using the SNPs only. Based on the alignment of the nucleotide sequences and constructed phylogenetic tree, it is clear that the T. urartu (PI428198) haplotype is evolutionarily distant from all others (Figure 3). The haplotype of wild emmer T. dicoccoides (Zavitan) was much closer to the haplotypes of bread wheat, although it has significant differences from them. Bread wheat haplotypes were divided into six groups. The older group includes T. spelta (haplotype a.17), as well as haplotypes $a .2, a .3, a .8, a .11$ and $a .12$ of bread wheat. There were also five younger groups: (1) a group that includes haplotypes of Chinese Spring (a.1) and Novosibirskaya $67(d .1) ;(2)$ a group that includes all $b$ haplotypes (b.1 .. b.5); (3) a group that includes haplotypes a.6 (Velena) and $a .13$ (Paragon); (4) haplotype $a .10$ (CDC Landmark); (5) haplotype $a .4$ (Grom). The last two groups include only one haplotype. Judging by the alignment of nucleotide sequences, the differences between haplotypes within the same group are due either to the presence of indels (in case of $d .1, c .1$ and a.16), or to a change in the length of the microsatellite in the $5^{\prime} \mathrm{UTR}$.

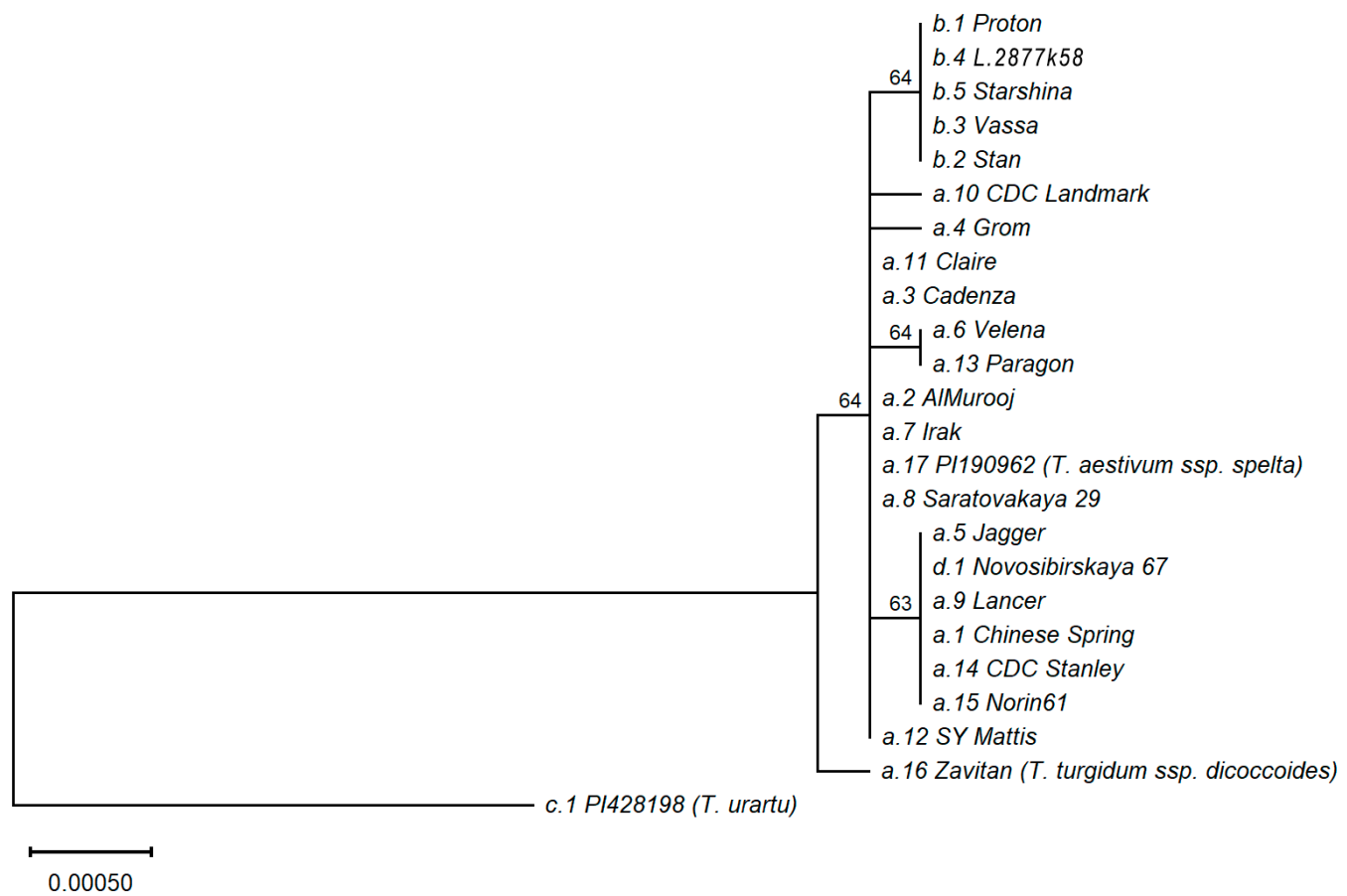

Figure 3. Molecular phylogenetic tree (subtree) of GRF3-2A haplotypes (gene + flanking sequences). To find a root, GRF3-2B gene of Chinese Spring was taken as an outgroup (not shown here). Bootstrap values are shown above nodes. At the tree leaves the Grf3-2A haplotypes and representative wheat accessions are indicated. If not specified, the accessions are Triticum aestivum L. ssp. aestivum.

\subsection{Molecular Markers and Phenotype}

We designed subgenome-specific primers to detect the 9-nucleotide deletion in the second exon of the GRF3-2A gene that was found in Novosibirskaya 67 (see Section 4). The PCR with DNA of the Novosibirskaya 67 gave a fragment of 335 base pairs (bp) of expected size (Figure 4a). Screening of 199 winter bread wheat accessions from a collection of the National Center of Grain (Krasnodar, Table S4) showed that among them there was only the $344 \mathrm{bp}$ variant of the marker. This suggests that the Novosibirskaya 67 cultivar carries a rare mutation of the GRF3-2A gene. 


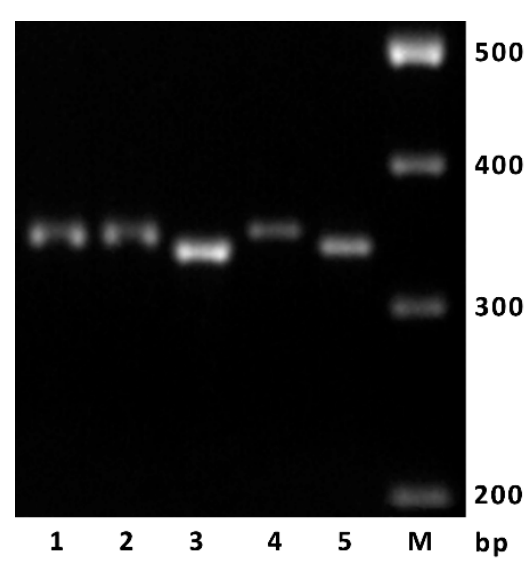

(a)

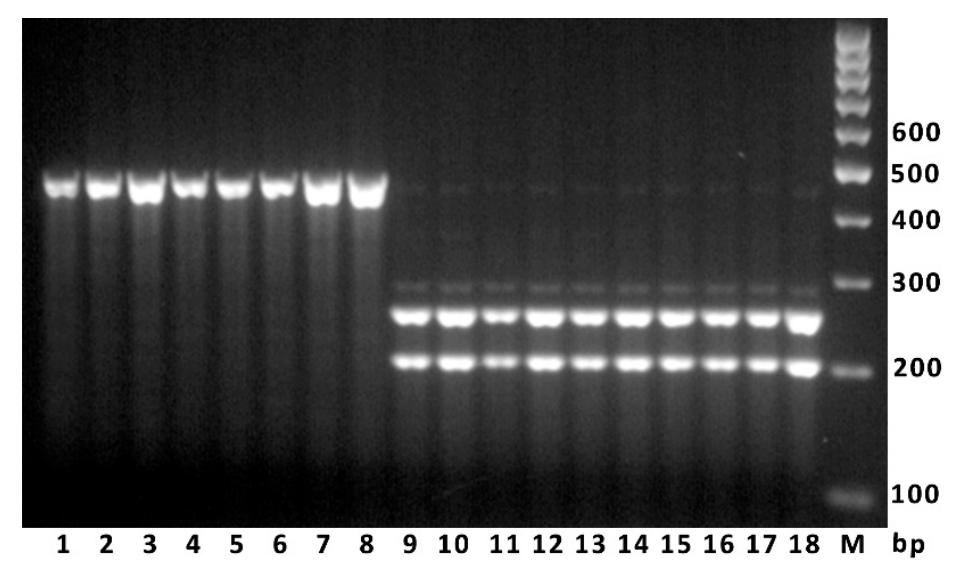

(b)

Figure 4. (a) An example of electrophoresis of the PCR marker designed for detecting the c.126_134del polymorphism. The PCR products were obtained using the primers GRF3A-Q42-F/R and DNA of the following wheat accessions: lane 1-Vid, 2-Stan, 4-Altigo, 3 and 5-Novosibirskaya 67, M-size standard M-100 (Syntol LLC, Moscow). (b) An example of electrophoresis of the marker detecting the c.495G $>$ T polymorphism in GRF3-2A. The PCR products obtained using primers GRF3A-Q165-F/R and digested using $S f a \mathrm{~N}$ I endonuclease. Lanes 1-8-accessions having the GRF3-2Aa allele (nucleotide G), two lanes each: Grom, Altigo, Velena, Sila; lanes 9-18-accessions having the GRF3-2Ab allele (nucleotide T), two lanes each: Vassa, Proton, Alekseich, Vid, Stan. M-size standard M-100.

A marker designed for detection of the c.495G $>$ T mutation resulting in amino-acid substitution, p.(Gln165His), was successfully validated on the DNA of wheat accession in which the GRF3-2A gene was sequenced (Figure $4 \mathrm{~b}$ ).

When a pool of 199 winter bread wheat accessions was analyzed using this marker, we found that the variant $\mathrm{T}$ of the polymorphism c.495G $>\mathrm{T}$ inherent to GRF3-2Ab allele was present in almost 39\% of accessions (Table S5). GRF3-2Ab, found in Bezostaya 1 and Krasnodarskaya 6 (old Russian cultivars), was in $46 \%$ of modern Russian cultivars, and was also detected in some Bulgarian, Chinese, Polish, Romanian, Ukrainian, USA and Yugoslavian cultivars, most of which, but not all, have Bezostaya 1 in their pedigrees. Cultivars from Austria, the Czech Republic, France, Germany, Hungary, and the UK that were tested did not have GRF3-2Ab. Due to low numbers of accessions from countries other than Russia, we cannot assert statistically significant differences of allele frequencies between different geographical locations.

Statistical analysis of phenotypic data for 199 winter bread wheat accessions collected over three years (2018-2020) at Krasnodar showed that the GRF3-2Ab allele (T variant at c.495G $>$ T polymorphism) in each of the three years was significantly associated with earlier heading ( $p \leq 0.02$, Fisher's F-test) and higher test weight of the grain $(p \leq 0.01)$ compared to the GRF3-2Aa allele (Figure 5). In one year, a positive association of the GRF3-2Ab allele with 1000 kernel weight $(2019, p<0.01)$ and a high grain protein content $(2018, p=0.01)$ was revealed. However, in 2018 , the grain yield was significantly lower for winter wheat accessions with the GRF3-2Ab allele, which presumably was associated with lower either grain numbers per spike or tillers per plant. However, the protein yield per hectare was non-significantly decreased in accessions carrying GRF3-2Ab in 2018 (Figure S2). Mean values of agronomic traits among wheat accessions having different alleles of the c.495G > T polymorphism are represented in Table S7.

Comparison of the 5'UTR microsatellite among sequenced GRF3-2A haplotypes and haplotypes obtained from sequenced wheat genomes gave 18 different lengths of the tandem repeat (Figure 1). However, the GRF3-2AD-SSR marker tested on the 199 winter wheat accessions showed only nine of those variants. That could be explained by the different accessions that were sequenced and genotyped. Statistical analysis showed significant connection between the microsatellite marker and the agronomic traits (Figures S3 and S4). Mean values of agronomic traits among wheat accessions having different alleles of the 
microsatellite are represented in Table S8. However, the same microsatellite size was observed for different gene alleles, including those that code different protein isoforms (Figure 1).

Heading date, d.a.s. *

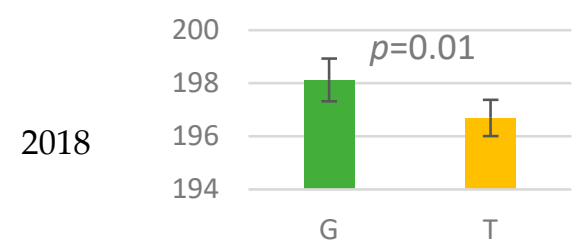

2019

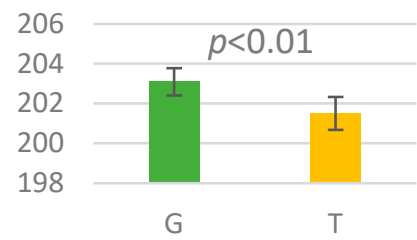

2020
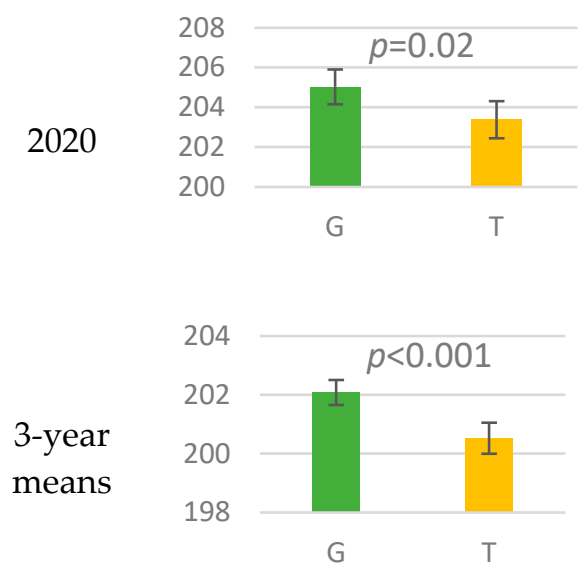

Test weight, g/l
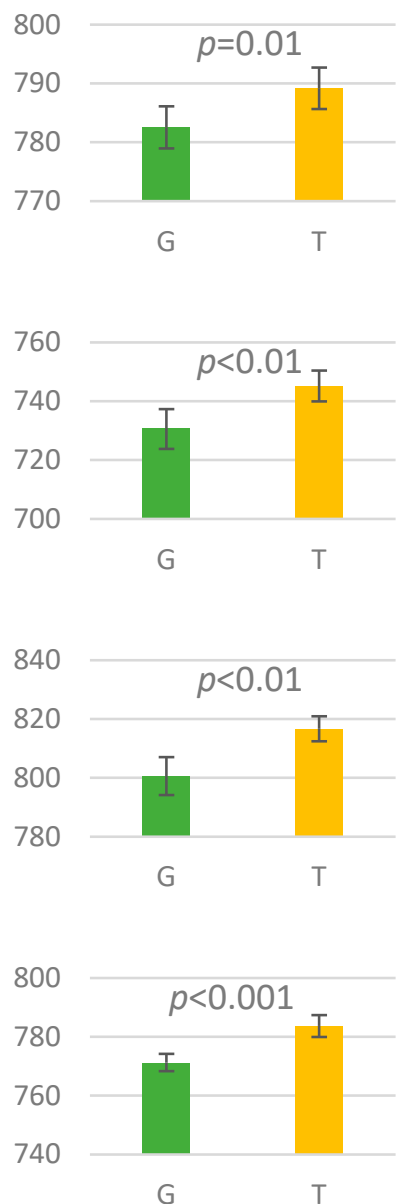

1000 kernel weight, $g$
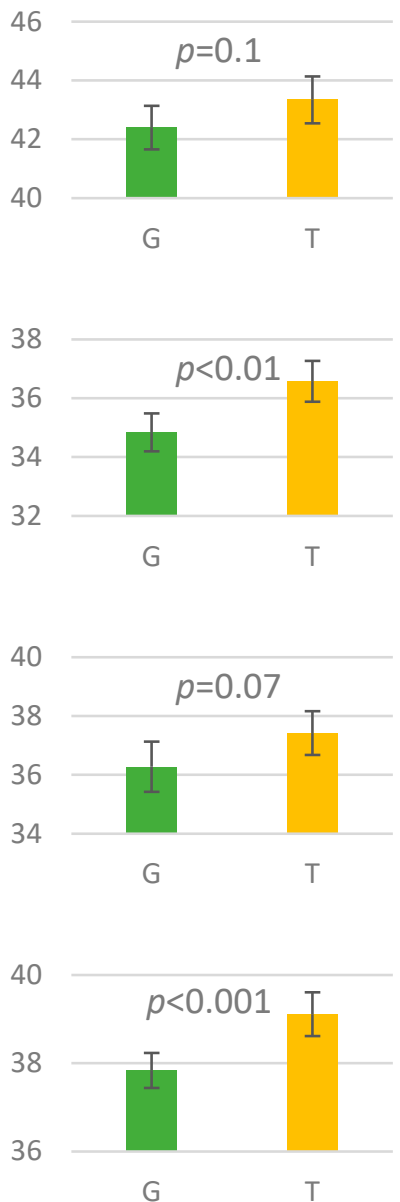

Figure 5. Heading date and grain traits for winter wheat accessions differing in missense mutation c.495G $>$ T in TaGRF3-2A tested in 2018-2020 at Krasnodar. Bars indicate 95\% confidence intervals. The $p$-values are calculated for Fisher's F-test. *-days after sowing.

\section{Discussion}

As expected for a functional gene prone to natural selection, most of the polymorphisms in GRF3-2A were detected in the non-coding regions and flanking sequences, while coding sequences were more conserved.

The GRF3-2A haplotypes of ancestral wild wheat species were evolutionary distant from the haplotypes of the bread wheat cultivars, indicating that wild species might serve as a source for the new alleles for investigation and crop improvement.

Although the observed polymorphisms in the promotor, $5^{\prime}$ and $3^{\prime}$ UTR do not change the protein sequence, they could alter the level of the RNA transcripts and translated protein. Mutations in the promoter can alter the number and composition of the cis-acting elements, recognized by transcription factors [21], while mutations of the DNA sequence in the region of the polyadenylation signal can affect the length of the mRNA and the presence of targets for microRNA and other post-transcriptional regulation factors in it [22]. The length of the 5'UTR microsatellite could also influence the level of gene expression [23].

Spring bread wheat cultivar Novosibirskaya 67 had a rare mutation that was not reported for this gene before- a deletion of nine nucleotides in the second exon, leading 
to a deletion of three glutamine residues from the protein molecule. We designated this mutation as TaGRF3-2Ad, corresponding to protein isoform D. The PROVEAN prediction, based on the change in alignment score of the amino-acid sequence to itself and to other related sequences in the database, showed that the biological function of the GRF3-2A protein should not be significantly altered by this mutation. Novosibirskaya 67 was one of the most widely grown spring wheat cultivars in Siberia since 1974 until the end of the 20th century. It was bred from a population of mutants obtained from the cultivar Novosibirskaya 7 following radiation [24]. We did not find the TaGRF3-2Ad allele in any other wheat cultivar, thus we assume that this mutation resulted from artificial mutagenesis, and may confer some adaptive traits to Novosibirskaya 67 . The agronomic value of the TaGRF3-2Ad allele would become the subject of further study.

The c.495G $>$ T missense mutation found in our study was present in many Russian winter wheat cultivars. We designated the allele carrying this mutation as TaGRF3-2Ab. It is present in almost half of the modern cultivars developed at the National Center of Grain at Krasnodar and is present in the old cultivars Bezostaya 1 and Krasnodarskaya 6. Previously, this mutation was reported in the results of the 1000 wheat exomes project and mapped to the reference wheat genome (IWGSC RefSeq v1.0) at coordinate chr2A:687050412 [25]. Among 811 wheat accessions tested in that project, the c.495G $>$ T missense mutation was found in only $3 \%$ of genotypes, including cultivars from the former USSR, Bulgaria, Argentina, Mexico, and some other countries.

Statistical analysis of the agronomic traits tested in 199 wheat accessions grown in Krasnodar during the three years showed that the TaGRF3-2Ab allele is associated with earlier heading and better grain filling as judged by the test weight and 1000 kernel weight. However, in some years TaGRF3-2Ab was associated with lower grain yield per hectare. In separate years, as in 2018, the mean yield of the cultivars and lines carrying GRF3-2Ab was even lower than in those carrying GRF3-2Aa. Most likely, GRF3-2Ab acts through the restriction of additional tillering at the late development stages of the plant, which releases the resources of assimilates for grain formation. This assumption has not been tested directly yet, but it can explain the observations. For winter wheat that may be exposed to severe winter conditions or even to drought in spring, which may become more often due to global warming, additional tillering may be favorable for the recovery of the crop. Although GRF3-2Ab may be good at maintaining the high milling quality of the grain, we think it should be used with caution in breeding of winter wheat cultivars from the perspective of climate change.

The TaPPD1-2A gene (TraesCS2A02G081900) in chromosome 2A that can affect earliness [26] is located at a considerable physical distance from TaGRF3-2A, probably on the other chromosome arm. Thus, the early heading associated with the TaGRF3-2Ab allele is unlikely to be explained by genetic linkage with the PPD1 gene. Other genes that could affect earliness, such as Vrn-1 (Vernalization) or Eps-1 (Earliness per se) are located on other chromosomes $[27,28]$. However, the presence of a nearby gene linked to TaGRF3-2A and affecting earliness cannot be excluded. We screened numerous genome-wide association studies reporting SNP markers connected with agronomic traits, and found no one significant marker-trait association that hit exactly the locus of the TaGRF3-2A. However, we found two markers associated with heading time-BobWhite_c16923_64 and wsnp_Ex_c14953_23104041-which surround the TaGRF3-2A and are 128 and 42 mega base pairs (Mbp) distant from it correspondingly [29]. Also, a marker BS00009247 on chromosome $2 \mathrm{~B}$ located $11 \mathrm{Mbp}$ from TaGRF3-2B - a homeolog of the gene studied-was associated with heading time [30]. Further fine mapping and gene engineering experiments are needed to postulate the causal relationship between TaGRF3-2A and the phenotype.

Breeding for early maturity and plump grain, together with the initial germplasm used, can explain the high frequency of TaGRF3-2Ab in Russian cultivars. Bezostaya 1 is present in pedigrees of the most modern Russian winter wheat cultivars, and thus is the probable source of the TaGRF3-2Ab allele in them. Bezostaya 1 probably obtained this allele from the old cultivar Ukrainka [25], or from Krymka (a Crimean landrace) [31,32] 
both of which are in the pedigree of Bezostaya 1 and other cultivars carrying TaGRF3-2Ab, but not having Bezostaya 1 or Ukrainka in pedigree. The presence of the TaGRF3-2Ab in Krymka could explain its presence in some American (USA) cultivars [33]. Generally, we can assume that $T a G R F 3-2 A b$ was present in multiple local cultivars (landraces) grown in lands surrounding the Black Sea before the beginning of the scientific breeding.

\section{Materials and Methods}

\subsection{Plant Material and Phenotyping}

Most of the wheat accessions used for sequencing GRF3-2A, genotyping and phenotyping were a part of the winter bread wheat collection maintained at the National Center of Grain named after P. P. Lukyanenko in Krasnodar (Table S4). Spring wheat accessions from Iraq were provided by Dr. Oleg G. Semenov (Department of Technosphere Safety, Agrarian-Technological Institute, RUDN University, Moscow). Other spring wheat accessions used for DNA extraction, PCR and sequencing were a part of a mini-collection maintained by the authors in Moscow (Table S1).

Yield testing and phenotyping for other parameters of the 199 winter wheat accessions was conducted according to the "Competitive variety testing methodologies" during the 2018-2020 harvest years at Krasnodar [34]. The experiments were laid in randomized complete block design on $25 \mathrm{~m}^{2}$ field plots in 4 replications. 1000 kernel weight was determined using a SEED COUNTER S-25 device (DATA Detection Technologies Ltd., Kibbutz Tzora, Israel) and electronic scales. Test weight, grain moisture content, and grain protein content were measured on $700 \mathrm{~g}$ samples using an Infratec 1241 grain analyzer (FOSS, Hilleroed, Denmark). Grain yield was determined as grain mass at $14 \%$ moisture content divided by plot area excluding the area of damaged sites. The heading date was recorded when $75 \%$ of plants showed at least a $50 \%$ spike emergence from the flag leaf sheath. Mean values of the measurements in each year were used for statistics regarding molecular markers.

\subsection{Weather Conditions}

The weather conditions during the vegetation periods in 2017-2020 for winter wheat at Krasnodar are represented in the Figures S5 and S6. The weather data were provided by the nearest meteorological station. The sowing of winter wheat was done on 21 October (both in 2017 and in 2018), and on 17 October in 2020. All three crop years were characterized by a dry period during seedbed preparation at the beginning of autumn and warm winters with no hard frosts and low precipitation, during which the plants maintained slow growth The booting stage was observed in the last third of March, while heading and anthesis occurred at the beginning of May in each year. In 2018 March was wet, and from April to the end of vegetation the precipitations were lower than average. This resulted in partial loss of young tillers in 2018. The spring of the 2019 was close to the climatic average. March and April of the 2020 were characterized by severe rainfall deficiency and recurrent frosts that caused partial loss of the main stems of early-maturing lines, while in May rainfall was higher than average. Grain filling and maturation during all three years occurred under conditions of high temperature and low humidity.

\subsection{DNA Extraction, PCR and Sequencing}

Genomic DNA was extracted from dried ground leaves of seedlings using the CTAB protocol [35]. The sequence of TaGRF3-2A (TraesCS2A02G435100) with about 1000 base pairs (bp) of flanking sequence, as well as the sequences of its homeologs on chromosome 2B and 2D (TraesCS2B02G458400 and TraesCS2D02G435200), were obtained from the annotated wheat genome assembly IWGSC RefSeq v1.0 using genome browser [17]. Specific primer pairs giving overlapping PCR products were designed using Primer-BLAST (NCBI) [36] to amplify the entire TaGRF3-2A sequence with a $1000 \mathrm{bp}$ promotor region (Table 2). The specificity of the primers was rechecked using alignment of the three homoeologous genes. 
Table 2. Primers used for PCR-amplification of the TaGRF3-2A fragments.

\begin{tabular}{ccc}
\hline Primer Sequence, $\mathbf{5}^{\prime} \rightarrow \mathbf{3}^{\prime}$ & $\mathbf{T m},{ }^{\circ} \mathbf{C}$ & Expected Product Size, $\mathbf{b p}$ \\
\hline $\begin{array}{c}\text { GRF-2A-1F: AAATTGAAGGCTAGACAATCGGC } \\
\text { GRF-2A-1R: CCTTTTACTCCTACTTGCCTGGT }\end{array}$ & 60 & 1179 \\
\hline $\begin{array}{c}\text { GRF-2A-2F: CAAACGAACTTGACGGTACAGAT } \\
\text { GRF-2A-2R: CACATGAGGATGAGGCTTCTTGA }\end{array}$ & 60 & 1188 \\
\hline $\begin{array}{l}\text { GRF-2A-3F: AGATTTCAGGTGTACTCGACCTC } \\
\text { GRF-2A-3R: AGCATGCAGAAGATAAAAACGGC }\end{array}$ & 60 & 1185 \\
\hline $\begin{array}{l}\text { GRF-2A-4F: GCTCAGCTGCACATGGATAATG } \\
\text { GRF-2A-4R: CGAGTCAGATTTGCAGCATAGTG }\end{array}$ & 60 & 1119 \\
\hline $\begin{array}{l}\text { GRF-2A-5F: TGCAGCAACAATTGCTCGTATAG } \\
\text { GRF-2A-5R: CACCCCCACCCCTAAGATAGATA }\end{array}$ & 60 & 1250 \\
\hline
\end{tabular}

PCR was performed in $25 \mu \mathrm{L}$ reaction volumes, containing $70 \mathrm{mM}$ Tris- $\mathrm{HCl}$ buffer ( $\mathrm{pH}$ 9.3), $16.6 \mathrm{mM}\left(\mathrm{NH}_{4}\right)_{2} \mathrm{SO}_{4}, 2.5 \mathrm{mM} \mathrm{MgCl} 2,0.2 \mathrm{mM}$ of each dNTP, $0.3 \mu \mathrm{M}$ forward and reverse primers (Sintol Ltd., Moscow, Russia), $0.04 \mathrm{U} / \mu \mathrm{L} L \mathrm{LR}$ (long reading) Plus polymerase (Sileks Ltd., Moscow, Russia), $0.02 \mathrm{U} / \mu \mathrm{L}$ Taq polymerase (Sileks Ltd.), and $4 \mathrm{ng} / \mu \mathrm{L}$ DNA template. PCR conditions were as follows: (1) $95{ }^{\circ} \mathrm{C}$ for $10 \mathrm{~min}$, (2) 45 cycles of $95{ }^{\circ} \mathrm{C}$ for $30 \mathrm{~s}, 60^{\circ} \mathrm{C}$ for $30 \mathrm{~s}, 72{ }^{\circ} \mathrm{C}$ for $4 \mathrm{~min}$; and (3) final extension step of $72{ }^{\circ} \mathrm{C}$ for $10 \mathrm{~min}$. PCR products were separated in 1.5\% agarose gels in TBE $(90 \mathrm{mM}$ Tris, $\mathrm{pH} 8.3,90 \mathrm{mM}$ boric acid, $0.1 \mathrm{mM}$ EDTA) buffer using GeneRuler $100 \mathrm{bp}$ Plus DNA Ladder (Thermo Fisher Scientific, Waltham, MA, USA) as a molecular weight marker, and stained with ethidium bromide for subsequent visualization in Gel Doc XR+ (Bio-Rad Laboratories, Inc., Hercules, CA, USA).

In cases of successful amplification, the PCR products obtained from DNA of the same wheat plant were mixed and submitted for NGS sequencing on Illumina MiSeq system. Sequencing was performed at "Genomed, Ltd." (Moscow, Russia). DNA libraries were prepared using Swift $2 \mathrm{~S}^{\mathrm{TM}}$ Turbo DNA Library Kits. In the process of library preparation, the contents of each tube, corresponding to a single wheat plant, were labelled with individual DNA barcodes. The gene sequences for each wheat plant were reconstructed using the previously published algorithm [37,38]. The 19 wheat accessions in which the TaGRF3-2A gene was sequenced in this way are listed in Table S1.

\subsection{Sequences Obtained from Genome Assemblies}

GRF3-2A sequences were obtained from the assembled genomes of bread wheat [16], durum wheat [39], spelt [16], T. urartu [19] and wild emmer [18] wheat (Table S6). The rough coordinates of GRF3-2A sequences were found in the genomes using the BLAST+ command line tool [40]. Using these coordinates, the sequences with extended margins were extracted from the genome FASTA files using a program written in Python [41].

\subsection{Sequence Analysis and Phylogenetics}

The sequences of TaGRF3-2A gene obtained experimentally along with others found in assemblies of wheat genomes were aligned using the MUSCLE algorithm in MEGA X software $[42,43]$. The exons and protein-coding sequences were detected using alignment with such sequences annotated for TraesCS2A02G435100 in IWGSC RefSeq v1.0. The translation of coding DNA sequence to an amino acid sequence was performed in GeneDoc 2.7 software [44].

Protein domains were identified using a Conserved Domains Database search at the NCBI website [45]. The functional significance of amino acid substitutions was predicted using the PROVEAN online service [46].

Evolutionary analyses of the TaGRF3-2A DNA sequences including a 1000 bp promotor were conducted in MEGA $X$ software using the maximum-likelihood method and Hasegawa-Kishino-Yano model [47]. All positions containing gaps and missing data 
were eliminated. The evolutionary tree of protein sequences was constructed using the maximum-likelihood method and Jones-Taylor-Thornton (JTT) model [48]. All sites, including gaps, were used. For both DNA and protein phylogenetic analyses, bootstrap support values were calculated using 500 replicates. The trees were drawn to scale, with branch lengths measured by numbers of substitutions per site. To establish a tree root, the homologs from wheat subgenome B and D were added as outgroups.

The analysis of the promoter sequence for the presence of transcription factor binding sites was done using the PlantPAN 3.0 database [21].

\subsection{Pedigrees}

The pedigrees of the wheat accessions studied were obtained from the Genetic Resources Information System for Wheat and Triticale website [49], or from the website of the State Commission for Selection Achievements Test and Protection (Russia) [50].

\subsection{Molecular Markers}

For detection of the 9-nucleotide deletion c.126_134del resulting in deletion of the three aminoacid residues p.(Gln42_Gln44del) of the GRF3 protein, we designed a pair of primers giving PCR products of 335 or 344 base pairs: GRF3A-Q42-F: 5' -CTTCTATCTGTAGCTCGAGGTGT-3' and GRF3A-Q42-R: 5'-GTGGTAGGAGGAGGAGGAATCTA-3'.

PCR was performed in $25 \mu \mathrm{L}$ reaction volumes, containing $70 \mathrm{mM}$ Tris- $\mathrm{HCl}$ buffer ( $\mathrm{pH}$ 8.6), $16.6 \mathrm{mM}\left(\mathrm{NH}_{4}\right)_{2} \mathrm{SO}_{4}, 2.5 \mathrm{mM} \mathrm{MgCl} 2,0.2 \mathrm{mM}$ of each dNTP, $0.3 \mu \mathrm{M}$ forward and reverse primers (Sintol Ltd., Moscow, Russia), $0.05 \mathrm{U} / \mu \mathrm{L}$ Taq polymerase (Sileks Ltd., Moscow, Russia), $4 \mathrm{ng} / \mu \mathrm{L}$ DNA template. The PCR conditions were as follows: (1) $95{ }^{\circ} \mathrm{C}$ for $10 \mathrm{~min}$, (2) 36 cycles of $95^{\circ} \mathrm{C}$ for $30 \mathrm{~s}, 60{ }^{\circ} \mathrm{C}$ for $30 \mathrm{~s}, 72{ }^{\circ} \mathrm{C}$ for $1 \mathrm{~min}$; and (3) final extension step of $72^{\circ} \mathrm{C}$ for $10 \mathrm{~min}$. PCR products were separated in $2 \%$ agarose gels with TBE buffer for at least $1 \mathrm{~h}$ in an electric field intensity of $6 \mathrm{~V} / \mathrm{cm}$ and visualized as described above.

To detect missense mutation c.495G > T leading to amino-acid change p.(Gln165His) we designed a pair of primers: GRF3A-Q165-F: 5'-GGGTTTTCTTAATTTGCTTGCAGT-3', GRF3A-Q165-R: 5'-CAGAAGATAAAAACGGCAGGTGA-3'. The PCR conditions were as described above. The PCR product of $454 \mathrm{bp}$ was subjected to endonuclease digestion using SfaN I enzyme (SibEnzyme Ltd., Novosibirsk, Russia) having recognition site GCATC(5/9)^. In a case of nucleotide $\mathrm{T}$ in the $\mathrm{c}$. $95 \mathrm{G}>\mathrm{T}$ polymorphism (resulting in histidine in the protein chain), the PCR product were digested into 201 and 253 bp products, while in the case of nucleotide $G$, the PCR product remained intact. The products of digestion were separated into $1.5 \%$ agarose gels in a TBE buffer using GeneRuler 100 bp DNA Ladder (Thermo Fisher Scientific, Waltham, MA, USA) as a molecular weight marker, and stained with ethidium bromide for subsequent visualization in Gel Doc XR+ (Bio-Rad Laboratories, Inc., Hercules, CA, USA).

For detection of simple sequence repeat length polymorphism in the $5^{\prime} \mathrm{UTR}$ of the TaGRF3$2 A$ gene we used primer pair GRF3-2AD-SSR-F: 5'-TCTCACCAGGCAGCAGATCG-3' and GRF3-2AD-SSR-R: 5' $5^{\prime}$ ACAGGGAGGCAAAGGGCATC-3' ${ }^{\prime}$ which was also suited to the TaGRF3-2D gene. The reverse primer was 5'-labelled with 6-carboxyfluorescein. As predicted by gene sequencing, the length of the PCR products for the TaGRF3-2A gene was expected in range 230 to $282 \mathrm{bp}$, whereas for TaGRF3-2D the expected sizes were 211 to $223 \mathrm{bp}$ [51]. Thus, the PCR-product sizes of TaGRF3-2A and TaGRF3-2D genes do not overlap. The PCR products were diluted 100 times and subjected to fragment analysis on a Nanofor-05 genetic analyzer (Sintol Ltd., Moscow) using a fluorescent fragment size standard SD-450 (Sintol Ltd.).

\subsection{Statistical Analysis}

Calculation of means, analysis of variance and confidence intervals were done in the Statistica 6.0 software package. Three-year means of agronomic traits for genotypes were calculated as least square means in two-way analysis of variance, where a year was one 
of the factors. Fisher's exact test for score traits was performed in the R programming language [52].

\section{Conclusions}

We studied the allelic diversity of the GRF3-2A gene in bread wheat and compared bread wheat alleles with those in some wild ancestral species. The allele designated as $T a G R F 3-2 A b$ was rare in a world wheat collection, but was quite common among Russian winter wheat cultivars. This allele was associated with earlier heading and better grain filling, while keeping almost the same yield per hectare. We can assume that this allele is adaptive for the steppes of the Black Sea region. We discovered a unique mutation of TaGRF3-2A in spring wheat cultivar Novosibirskaya 67 , the agronomic value of which is yet to be established.

Supplementary Materials: The following are available online at https:/ /www.mdpi.com/article/10 $.3390 /$ ijms222212376/s1.

Author Contributions: Conceptualization, M.G.D.; methodology, M.G.D. and M.S.B.; software, M.S.B.; formal analysis, M.S.B.; investigation, A.G.C., N.A.P., T.I.G. and L.A.N.; resources, L.A.B.; data curation, L.A.B., N.A.P., T.I.G.; writing—original draft preparation, M.S.B.; writing—review and editing, M.G.D. and L.A.B.; visualization, A.G.C. and L.A.N.; supervision, G.I.K.; project administration, M.G.D.; funding acquisition, M.G.D. All authors have read and agreed to the published version of the manuscript.

Funding: This research was funded by the Ministry of Science and Higher Education of the Russian Federation, state task number 0431-2019-0004.

Institutional Review Board Statement: Not applicable.

Informed Consent Statement: Not applicable.

Data Availability Statement: The data presented in this study are available in Supplementary Materials to this article. The sequences of the TaGRF3-2A gene obtained in this study were deposited to NCBI GenBank under accession numbers OK094721-OK094732.

Acknowledgments: We are greatly thankful to Oleg G. Semenov (Department of Technosphere Safety, Agrarian-Technological Institute, RUDN University, Moscow), who provided spring wheat accessions from Iraq for our studies.

Conflicts of Interest: The authors declare no conflict of interest.

\section{References}

1. Huang, W.; He, Y.; Yang, L.; Lu, C.; Zhu, Y.; Sun, C.; Ma, D.; Yin, J. Genome-Wide Analysis of Growth-Regulating Factors (GRFs) in Triticum Aestivum. PeerJ 2021, 9, e10701. [CrossRef]

2. van der Knaap, E.; Kim, J.H.; Kende, H. A Novel Gibberellin-Induced Gene from Rice and Its Potential Regulatory Role in Stem Growth. Plant. Physiol. 2000, 122, 695-704. [CrossRef]

3. Kim, J.H.; Choi, D.; Kende, H. The AtGRF Family of Putative Transcription Factors Is Involved in Leaf and Cotyledon Growth in Arabidopsis. Plant. J. 2003, 36, 94-104. [CrossRef]

4. Liu, J.; Hua, W.; Yang, H.-L.; Zhan, G.-M.; Li, R.-J.; Deng, L.-B.; Wang, X.-F.; Liu, G.-H.; Wang, H.-Z. The BnGRF2 Gene (GRF2-like Gene from Brassica napus) Enhances Seed Oil Production through Regulating Cell Number and Plant Photosynthesis. J. Exp. Bot. 2012, 63, 3727-3740. [CrossRef] [PubMed]

5. Zan, T.; Zhang, L.; Xie, T.; Li, L. Genome-Wide Identification and Analysis of the Growth-Regulating Factor (GRF) Gene Family and GRF-Interacting Factor Family in Triticum aestivum L. Biochem. Genet. 2020, 58, 705-724. [CrossRef]

6. Kim, J.H.; Kende, H. A Transcriptional Coactivator, AtGIF1, Is Involved in Regulating Leaf Growth and Morphology in Arabidopsis. Proc. Natl. Acad. Sci. USA 2004, 101, 13374-13379. [CrossRef]

7. Li, S.; Tian, Y.; Wu, K.; Ye, Y.; Yu, J.; Zhang, J.; Liu, Q.; Hu, M.; Li, H.; Tong, Y.; et al. Modulating Plant Growth-Metabolism Coordination for Sustainable Agriculture. Nature 2018, 560, 595-600. [CrossRef]

8. Liebsch, D.; Palatnik, J.F. MicroRNA MiR396, GRF Transcription Factors and GIF Co-Regulators: A Conserved Plant Growth Regulatory Module with Potential for Breeding and Biotechnology. Curr. Opin. Plant Biol. 2020, 53, 31-42. [CrossRef] [PubMed]

9. Beltramino, M.; Debernardi, J.M.; Ferela, A.; Palatnik, J.F. ARF2 Represses Expression of Plant GRF Transcription Factors in a Complementary Mechanism to MicroRNA MiR396. Plant Physiol. 2021, 185, 1798-1812. [CrossRef] [PubMed] 
10. Gao, F.; Wang, K.; Liu, Y.; Chen, Y.; Chen, P.; Shi, Z.; Luo, J.; Jiang, D.; Fan, F.; Zhu, Y.; et al. Blocking MiR396 Increases Rice Yield by Shaping Inflorescence Architecture. Nat. Plants 2016, 2, 15196. [CrossRef]

11. Che, R.; Tong, H.; Shi, B.; Liu, Y.; Fang, S.; Liu, D.; Xiao, Y.; Hu, B.; Liu, L.; Wang, H.; et al. Control of Grain Size and Rice Yield by GL2-Mediated Brassinosteroid Responses. Nat. Plants 2016, 2, 15195. [CrossRef] [PubMed]

12. Kim, J.-S.; Mizoi, J.; Kidokoro, S.; Maruyama, K.; Nakajima, J.; Nakashima, K.; Mitsuda, N.; Takiguchi, Y.; Ohme-Takagi, M.; Kondou, Y.; et al. Arabidopsis GROWTH-REGULATING FACTOR7 Functions as a Transcriptional Repressor of Abscisic Acidand Osmotic Stress-Responsive Genes, Including DREB2A. Plant. Cell 2012, 24, 3393-3405. [CrossRef]

13. Duan, P.; Ni, S.; Wang, J.; Zhang, B.; Xu, R.; Wang, Y.; Chen, H.; Zhu, X.; Li, Y. Regulation of OsGRF4 by OsmiR396 Controls Grain Size and Yield in Rice. Nat. Plants 2015, 2, 1-5. [CrossRef]

14. Avni, R.; Oren, L.; Shabtay, G.; Assili, S.; Pozniak, C.; Hale, I.; Ben-David, R.; Peleg, Z.; Distelfeld, A. Genome Based Meta-QTL Analysis of Grain Weight in Tetraploid Wheat Identifies Rare Alleles of GRF4 Associated with Larger Grains. Genes $2018,9,636$. [CrossRef]

15. Tsukaya, H. Yield Increase: GRFs Provide the Key. Nat. Plants 2015, 2, 1-2. [CrossRef] [PubMed]

16. Walkowiak, S.; Gao, L.; Monat, C.; Haberer, G.; Kassa, M.T.; Brinton, J.; Ramirez-Gonzalez, R.H.; Kolodziej, M.C.; Delorean, E.; Thambugala, D.; et al. Multiple Wheat Genomes Reveal Global Variation in Modern Breeding. Nature 2020, 588, $277-283$. [CrossRef]

17. Alaux, M.; Rogers, J.; Letellier, T.; Flores, R.; Alfama, F.; Pommier, C.; Mohellibi, N.; Durand, S.; Kimmel, E.; Michotey, C.; et al. Linking the International Wheat Genome Sequencing Consortium Bread Wheat Reference Genome Sequence to Wheat Genetic and Phenomic Data. Genome Biol. 2018, 19, 111. [CrossRef] [PubMed]

18. Avni, R.; Nave, M.; Barad, O.; Baruch, K.; Twardziok, S.O.; Gundlach, H.; Hale, I.; Mascher, M.; Spannagl, M.; Wiebe, K.; et al. Wild Emmer Genome Architecture and Diversity Elucidate Wheat Evolution and Domestication. Science 2017, 357, 93-97. [CrossRef]

19. Ling, H.-Q.; Ma, B.; Shi, X.; Liu, H.; Dong, L.; Sun, H.; Cao, Y.; Gao, Q.; Zheng, S.; Li, Y.; et al. Genome Sequence of the Progenitor of Wheat A Subgenome Triticum Urartu. Nature 2018, 557, 424-428. [CrossRef]

20. den Dunnen, J.T.; Dalgleish, R.; Maglott, D.R.; Hart, R.K.; Greenblatt, M.S.; McGowan-Jordan, J.; Roux, A.-F.; Smith, T.; Antonarakis, S.E.; Taschner, P.E.M. HGVS Recommendations for the Description of Sequence Variants: 2016 Update. Hum. Mutat. 2016, 37, 564-569. [CrossRef]

21. Chow, C.-N.; Lee, T.-Y.; Hung, Y.-C.; Li, G.-Z.; Tseng, K.-C.; Liu, Y.-H.; Kuo, P.-L.; Zheng, H.-Q.; Chang, W.-C. PlantPAN3.0: A New and Updated Resource for Reconstructing Transcriptional Regulatory Networks from ChIP-Seq Experiments in Plants. Nucleic Acids Res. 2019, 47, D1155-D1163. [CrossRef]

22. Hong, L.; Ye, C.; Lin, J.; Fu, H.; Wu, X.; Li, Q.Q. Alternative Polyadenylation Is Involved in Auxin-Based Plant Growth and Development. Plant J. 2018, 93, 246-258. [CrossRef] [PubMed]

23. Kumar, S.; Bhatia, S. A Polymorphic (GA/CT)n- SSR Influences Promoter Activity of Tryptophan Decarboxylase Gene in Catharanthus roseus L. Don. Sci. Rep. 2016, 6, 33280. [CrossRef]

24. Artemova, G.V.; Likhenko, I.E. Historical aspects and main results of scientific research in SIBNIIRS-Branch of the Institute of Cytology and Genetics SO RAN. Lett. Vavilov J. Genet. Breed. 2016, 2, 3. Available online: http://pismavavilov.ru/2016-2-1/ (accessed on 16 November 2021).

25. He, F.; Pasam, R.; Shi, F.; Kant, S.; Keeble-Gagnere, G.; Kay, P.; Forrest, K.; Fritz, A.; Hucl, P.; Wiebe, K.; et al. Exome Sequencing Highlights the Role of Wild-Relative Introgression in Shaping the Adaptive Landscape of the Wheat Genome. Nat. Genet. 2019, 51, 896-904. [CrossRef]

26. Guo, W.; Xin, M.; Wang, Z.; Yao, Y.; Hu, Z.; Song, W.; Yu, K.; Chen, Y.; Wang, X.; Guan, P.; et al. Origin and Adaptation to High Altitude of Tibetan Semi-Wild Wheat. Nat. Commun. 2020, 11, 5085. [CrossRef] [PubMed]

27. Alvarez, M.A.; Tranquilli, G.; Lewis, S.; Kippes, N.; Dubcovsky, J. Genetic and Physical Mapping of the Earliness per Se Locus Eps-Am1 in Triticum monococcum Identifies EARLY FLOWERING 3 (ELF3) as a Candidate Gene. Funct. Integr. Genom. 2016, 16, 365-382. [CrossRef] [PubMed]

28. Santra, D.K.; Santra, M.; Allan, R.E.; Campbell, K.G.; Kidwell, K.K. Genetic and Molecular Characterization of Vernalization Genes Vrn-A1, Vrn-B1, and Vrn-D1 in Spring Wheat Germplasm from the Pacific Northwest Region of the U.S.A. Plant. Breed. 2009, 128, 576-584. [CrossRef]

29. Zanke, C.; Ling, J.; Plieske, J.; Kollers, S.; Ebmeyer, E.; Korzun, V.; Argillier, O.; Stiewe, G.; Hinze, M.; Beier, S.; et al. Genetic Architecture of Main Effect QTL for Heading Date in European Winter Wheat. Front. Plant. Sci. 2014, 5, 217. [CrossRef] [PubMed]

30. Gao, L.; Zhao, G.; Huang, D.; Jia, J. Candidate Loci Involved in Domestication and Improvement Detected by a Published 90K Wheat SNP Array. Sci. Rep. 2017, 7, 44530. [CrossRef]

31. KRYMKA. Available online: http:/ / wheatpedigree.net/sort/show/32936 (accessed on 29 July 2021).

32. CRIMEAN. Available online: http:/ / wheatpedigree.net/sort/show/14818 (accessed on 29 July 2021).

33. Moon, D. Introduction of Russian wheat in the Great Plains of the United States of America. In American Yearbook 2011; Ves' Mir: Moscow, Russia, 2011; pp. 161-176.

34. Competitive Variety Testing Methodologies. Available online: https://gossortrf.ru/en/metodiki_ksi/ (accessed on 6 September 2021).

35. Doyle, P.J. DNA Protocols for Plants. In Molecular Techniques in Taxonomy; Hewitt, G.M., Johnston, A.W.B., Young, J.P.W., Eds.; NATO ASI Series; Springer: Berlin/Heidelberg, Germany, 1991; ISBN 978-3-642-83964-1. 
36. Ye, J.; Coulouris, G.; Zaretskaya, I.; Cutcutache, I.; Rozen, S.; Madden, T.L. Primer-BLAST: A Tool to Design Target-Specific Primers for Polymerase Chain Reaction. BMC Bioinform. 2012, 13, 134. [CrossRef] [PubMed]

37. Bazhenov, M.S.; Chernook, A.G.; Goncharov, N.P.; Chikida, N.N.; Belousova, M.K.; Karlov, G.I.; Divashuk, M.G. The Allelic Diversity of the Gibberellin Signaling Pathway Genes in Aegilops tauschii Coss. Plants 2020, 9, 1696. [CrossRef] [PubMed]

38. MikhailBazhenov Consensus: A Program for Making Consensus Sequence from CAP3 Output. Available online: https://github. com/MikhailBazhenov/Consensus (accessed on 27 September 2021).

39. Fruzangohar, M.; Kalashyan, E.; Kalambettu, P.; Ens, J.; Wiebe, K.; Pozniak, C.J.; Tricker, P.J.; Baumann, U. Novel Informatic Tools to Support Functional Annotation of the Durum Wheat Genome. Front. Plant. Sci. 2019, 10, 1244. [CrossRef] [PubMed]

40. Camacho, C.; Coulouris, G.; Avagyan, V.; Ma, N.; Papadopoulos, J.; Bealer, K.; Madden, T.L. BLAST+: Architecture and Applications. BMC Bioinform. 2009, 10, 421. [CrossRef] [PubMed]

41. MikhailBazhenov Fastfinder: A Program for Extracting Some Part of a Sequence from a Genome-Large FASTA File. Available online: https: / github.com/MikhailBazhenov / fastfinder (accessed on 27 September 2021).

42. Edgar, R.C. MUSCLE: Multiple Sequence Alignment with High Accuracy and High Throughput. Nucleic Acids Res. 2004, 32, 1792-1797. [CrossRef] [PubMed]

43. Kumar, S.; Stecher, G.; Li, M.; Knyaz, C.; Tamura, K. MEGA X: Molecular Evolutionary Genetics Analysis across Computing Platforms. Mol. Biol. Evol. 2018, 35, 1547-1549. [CrossRef]

44. NICHOLAS, K.B. GeneDoc: Analysis and Visualization of Genetic Variation. EMBNEW News 1997, 4, 14.

45. Marchler-Bauer, A.; Derbyshire, M.K.; Gonzales, N.R.; Lu, S.; Chitsaz, F.; Geer, L.Y.; Geer, R.C.; He, J.; Gwadz, M.; Hurwitz, D.I.; et al. CDD: NCBI's Conserved Domain Database. Nucleic Acids Res. 2015, 43, D222226. [CrossRef]

46. Choi, Y.; Chan, A.P. PROVEAN Web Server: A Tool to Predict the Functional Effect of Amino Acid Substitutions and Indels. Bioinformatics 2015, 31, 2745-2747. [CrossRef]

47. Hasegawa, M.; Kishino, H.; Yano, T. Dating of the Human-Ape Splitting by a Molecular Clock of Mitochondrial DNA. J. Mol. Evol. 1985, 22, 160-174. [CrossRef]

48. Jones, D.T.; Taylor, W.R.; Thornton, J.M. The Rapid Generation of Mutation Data Matrices from Protein Sequences. Comput. Appl. Biosci. Cabios 1992, 8, 275-282. [CrossRef] [PubMed]

49. Genetic Resources Information System for Wheat and Triticale. Available online: http://wheatpedigree.net/ (accessed on 16 August 2021).

50. State Commission for Selection Achievements Test and Protection. Available online: https://gossortrf.ru/en/ (accessed on 16 August 2021).

51. Kroupin, P.Y.; Chernook, A.G.; Bazhenov, M.S.; Karlov, G.I.; Goncharov, N.P.; Chikida, N.N.; Divashuk, M.G. Allele Mining of TaGRF-2D Gene 5'-UTR in Triticum aestivum and Aegilops tauschii Genotypes. PLoS ONE 2020, 15, e0231704. [CrossRef] [PubMed]

52. R Core Team. R: A Language and Environment for Statistical Computing; R Foundation for Statistical Computing: Vienna, Austria, 2020. 